\title{
A construção da Cavalaria de Rei Arthur em Thomas Malory a partir do Juramento do Pentecostes
}

Willian Perpétuo Busch ${ }^{1}$

Resumo: Nossa inquirição almejou compreender como foi construída a noção de cavalaria presente no texto literário Le Morte D'Arthur, redigido por Sir Thomas Malory por volta de 1495. Como o título sugere, por se tratar de uma narrativa sobre "Rei Arthur", nosso primeiro passo foi compreender como essa figura foi construída entre a Antiguidade e o Medievo. Cruzamos as investigações sobre "Rei Arthur" com uma breve caracterização do fenômeno da "cavalaria" em seu contexto histórico, algo que fizemos a partir dos trabalhos de George Duby ${ }^{2}$, Jean Flori ${ }^{3}$ e Dominique Barthélemy ${ }^{4}$. Nossa revisão bibliográfica dividiu-se em três momentos distintos: I) referências sobre Malory e sua identidade (em disputa); II) contexto da Inglaterra durante a vida do autor; III) estudos acadêmicos que aproximam a imagética e o simbolismo em torno da figura do Rei Arthur com o Santo Graal e a cavalaria. Tal incursão nos permitiu visualizar como essa cavalaria que aparece na literatura de Malory estava fundada na confluência dos eixos: marcialidade; corte e sacralidade, reagindo a estes de forma crítica. Trata-se de uma cavalaria difusa que nos oferece um enquadramento para compreender como contradições, conflitos e tensões sociais do período reverberavam sobre a literatura. O núcleo disso aparece dentro da literatura de Malory na forma do Juramento do Pentecostes.

Palavras-Chave: Rei Arthur. Cavalaria. Thomas Malory.

${ }^{1}$ Mestre em Antropologia (UFPR) e mestrando no Programa de Pós-Graduação em História da Universidade Federal do Paraná. Contato: busch.wpb@gmail.com. Este artigo é fruto de uma Iniciação Científica Voluntária na Universidade Federal do Paraná realizada entre 2017 e 2018 sob orientação da Prof. Dra. Marcella Lopes Guimarães sob o título de: A circulação da informação entre os reinos ibéricos e a França nos séculos XIV e XV.

2 DUBY, Georges, As Três Ordens ou O Imaginário do Feudalismo, Lisboa: Estampa, 1994; DUBY, Georges, Sociedades Medievais, Lisboa: Terramar, 1999; DUBY, Georges, Ano 1000, Ano 2000 - Na Pista de Nossos Medos, São Paulo: UNESP, 1998.

${ }^{3}$ FLORI, Jean, Chevaliers et chevalerie au Moyen Age, Paris: Hachette Littératures, 1998.

${ }^{4}$ BARTHÉLEMY, Dominique, A Cavalaria - Da Germânia Antiga à França do século XII, Campinas: Editora da Unicamp, 2010.

Revista Vernáculo n. ${ }^{\circ} 43$ - primeiro semestre/2019

ISSN 2317-4021 
Abstract: Our inquiry sought to understand how the notion of cavalry present in the literary text Le Morte D'Arthur, written by Sir Thomas Malory around 1495, was constructed. As the title suggests, because it is a narrative about King Arthur, our first step was to understand how this figure was built between Antiquity and the Middle Ages. We cross the investigations on "King Arthur" with a brief characterization of the phenomenon of "cavalry" in its historical context, something that we did from the works of George Duby, Jean Flori and Dominique Barthélemy. Our bibliographic review was divided in three distinct moments: I) references about Malory and his identity (in dispute); II) context of England during the life of the author; III) academic studies that approximate the imagery and the symbolism around the figure of King Arthur with the Holy Grail and the cavalry. This incursion allowed us to visualize how this cavalry that appears in the literature of Malory was founded in the confluence of the axes: martiality; cut and sacrality, reacting to them critically. It is a diffuse cavalry that offers us a framework to understand how contradictions, conflicts and social tensions of the period reverberated about literature. The core of this appears within Malory's literature in the form of the Pentecost Pledge.

Keywords: Rei Arthur. Knighthood. Thomas Malory.

Narrativas, filmes, músicas — histórias — que orbitam a figura do Rei Arthur são constantes no imaginário ocidental ${ }^{5}$. Contos que revelam os feitos de cavaleiros como Sir Lancelot ${ }^{6}$ e Sir Gawain, somam-se com outros sobre a jornada do jovem Percival em busca do Santo Graal. A emblemática figura do mago Merlin é conhecida, bem como os planos sinistros de Morgan le Fay, e de Sir Mordred.

Qual o ponto de origem desse material constantemente imaginado nas produções artísticas? Como foi o processo histórico que

\footnotetext{
${ }^{5}$ ASHLEY, Mike, The Mammoth Book of King Arthur, New York: Carroll \& Graf Publishers, 2005.

${ }^{6}$ Optamos por deixar em itálico os nomes de personagens referentes as produções literárias.
} 
deu origem a isto? Sugerimos retornar para o fim do século VI d. C., para a ilha da Britannia ${ }^{7}$. Outrora província de Roma, o território passou a receber sucessivas ondas de povos germânicos que expulsaram a população romano-celta local entre os anos de 410 e $600^{8}$.

A história de Arthur, em uma das suas formas arcaicas ${ }^{9}$, surgiu em relação a este momento, a partir de Gildas Sapiens (500-570). No seu De Excidio et Conquestu Britanniae ${ }^{10}$, o monge cristão narrou como um chefe de guerra local foi responsável pela defesa dos territórios contra os invasores "bárbaros" pagãos.

A noção e a proeza militar desse chefe atravessarão o medievo e serão imaginadas e interpretadas por diferentes autores, como Chrétien de Troyes (fim do XII) ${ }^{11}$ e Sir Thomas Malory ${ }^{12}$. Na modernidade, por

${ }^{7}$ Em torno de questões pertinentes a Britannia, ver: CREIGHTON, John, Britannia The Creation of a Roman Province, London: Routledge, 2006; LAYCOCK, Stuart, Britannia The Failed State - Tribal Conflcits and the End of Roman Britain, Stroud: The History Press, 2008.

${ }^{8}$ CRAUGHWELL, Thomas J., How the Barbarian Invasions shaped the modern world - The Vikings, Vandals, Huns, Mongols, Goths, and Tartars who Razed the Old World and Formed the New, Singapore: Fair Wind Press, 2008; SAWYER, P. H., King and Vikings - Scandinavia and Europe AD 700-1100, London \& New York: Routledge, 1982.

${ }^{9}$ Convém lembrar que a narrativa de um rei que protege seu reino de invasores não era algo inédito. Há aspectos das histórias de Arthur que comungam com outros textos da Antiguidade. Ver: ANDERSON, Graham, King Arthur in Antiquity, London \& New York: Routledge, 2004.

${ }^{10}$ GILDAS, De Excidio et Conquestu Britanniae, Cambridge: Medieval Latin Series, 540.

${ }^{11}$ DE TROYES, Chrétien, Oeuvres complètes, Paris: Gallimard, 1994.

${ }^{12}$ MALORY, Sir Thomas, Le Morte D'Arthur. Vol. 1-2, London: Penguin Books, 1969.

Revista Vernáculo n. ${ }^{\circ} 43$ - primeiro semestre/2019

ISSN 2317-4021 
figuras como Edmund Spenser (1552-1599) ${ }^{13}$, Lord Alfred Tennyson $(1809-1892)^{14}$ e Wilhelm Richard Wagner $(1813-1883)^{15}$, para citar alguns poucos.

O que nos leva a uma primeira pergunta - o que conectou os feitos do guerreiro de Gildas, Ambrosius Aurelianus, protetor da província romana da Britannia no século V, com a cavalaria, o Santo Graal, a Távola Redonda, e os outros elementos que vieram a compor a história arthuriana?

Qualquer obra sobre Arthur que tenha sido produzida no medievo pode fornecer um ponto de partida. Nossa opção foi pela Le Morte $D^{\prime}$ Arthur $^{16}$, concebida por Sir Thomas Malory. Uma significativa empreitada que teve como objetivo organizar, de modo cronológico, coerente e sequencial a história de Arthur. Enquanto Gildas Sapiens escrevera para um mundo medieval que se organizava, Malory experimentou um momento diferente, no fim do século XIV. Dentro deste espaço temporal, os feitos do Rei Arthur e da sua "corte" circulavam pela tradição oral e escrita, não restrita ao inglês, mas também francês ${ }^{17}$, italiano, espanhol, alemão, nórdico e russo ${ }^{18}$.

${ }^{13}$ BURLINSON, Christopher, Allegory, Space and the Material World in the Writings of Edmung Spenser, Cambridge: D. S. Brewer, 2006.

14 LAMBDIN, Laura Cooner; LAMBDIN, Robert Thomas, Camelot in the Nineteenth Century - Arthurian Characters in the Poems of Tennyson, Arnold, Morris, and Swinburne, London: Greenwood Press, 2000.

${ }^{15}$ HÉBERT, Marcel, Religious Experience in the Work of Richard Wagner, Washington: The Catholic University of America Press, 2015.

${ }^{16}$ MALORY, Le Morte D'Arthur. Vol. 1-2.

${ }^{17}$ GREENE, Virginie (Org.), The Medieval Author in Medieval French Literature, New York: Palgrave Macmillan, 2006.

Revista Vernáculo n. ${ }^{\circ} 43$ - primeiro semestre/2019

ISSN 2317-4021 
O texto de Malory foi redigido em inglês médio ${ }^{19}$, por volta de 1468 e 1470, a fazer uso majoritário de fontes inglesas e francesas. O resultado (ou parte dele) foi publicado em 1485 por William Caxton (1422-1491). O ponto de diferenciação entre a escrita e a circulação foram a introdução da máquina de impressão em 1476 na Inglaterra por Caxton. Portanto, há um contraste entre o público-alvo de Malory e o de Caxton $^{20}$.

A noção de obra literária medieval, bem como a figura do autor, cruzam-se com práticas de transmissão cultural previamente enraizadas e que diferem do padrão contemporâneo. Como explicitou o historiador francês Jean Flori, "os autores medievais eram ouvidos, entendidos, lidos durante a vida; eles também eram, durante muito tempo, copiados e recopiados, traduzidos e imitados" ${ }^{21}$.

Tomando a cultura literária e documental da Inglaterra medieval $^{22}$, a principal análise contemporânea orientada para compreender a historicidade do Rei Arthur partiu de Leslie Alcock ${ }^{23}$

${ }^{18}$ HOWEY, Ann F.; REIMER, Stephen R. (Orgs.), A Bibliography of Modern Arthuriana 1500-2000, Cambridge: D. S. Brewer, 2006.

${ }^{19}$ DALRYMPLE, Roger (Org.), Middle English Literature - A Guide to Criticism, Malden: Blackwell Publishing, 2004.

${ }^{20}$ SAYLE, C. E., Early English Printed Books in the University Library, Cambridge, 1475 to 1640. Vol. 1: Caxton to F. Kingston, Cambridge: Cambridge University Press, 1900.

${ }^{21}$ Tradução nossa. No original: "les auteurs médiévaux furent écoutés, entendus, lus de leur vivant; ils furent aussi, et long-temp, copiés et recopíes, traduit et imités". FLORI, Chevaliers et chevalerie au Moyen Age, p. 235.

${ }^{22}$ Por "Inglaterra medieval" entendemos o agrupamento das ilhas britânicas.

${ }^{23}$ Professor de Arqueologia na Universidade de Glasgow, e um dos estudiosos mais importantes no que tange o período da Antiguidade Tardia.

Revista Vernáculo n. ${ }^{\circ} 43$ - primeiro semestre/2019

ISSN 2317-4021 
(1925-2006). Em Arthur's Britain - History and Archaeology AD 367$634^{24}$, publicado em 1971, Alcock iniciou por evidências documentais e de suas restrições, para desembocar em uma investigação sobre as possíveis contribuições da cultura material para a discussão.

$\mathrm{O}$ argumento de Alcock ganhou forma na medida em que as histórias sobre Arthur convergiram numa figura bélica e marcial da Britannia, que, como aparece em Gildas ${ }^{25}$, representava a população romano-celta local. As suas vitórias militares, mesmo que espaçadas e fragmentadas e sem total certeza sobre as datas específicas, números e locais, acabaram por armar um tipo figurativo de um líder que venceu os invasores saxões. Este, a nosso ver, é o núcleo básico da lenda.

Graham Anderson ${ }^{26}$, em King Arthur in Antiquity, de 2004 ${ }^{27}$, deslocou a discussão para o estudo comparativo de narrativas sobre realeza e proeza militar que perscrutam o campo nos estudos de Antiguidade. A sua conclusão é de que Arthur Pendragon, o modelo bretão, tem similaridades com Arktouros de Arcadia, Arktouros de Atenas, Ardus e Ardys da Lidia, e Lucius Artorius Castus.

O ponto comum entre Anderson e Alcock é Arthur como um líder bélico. Mesmo que a natureza da pesquisa de Anderson ${ }^{28}$ e Alcock seja diferente em recorte, escopo e conclusão, eles corroboram para

\footnotetext{
${ }^{24}$ ALCOCK, Leslie, Arthur's Britain - History and Archaeology AD 367-634, New York: Penguin Books, 1971.

${ }^{25}$ GILDAS, De Excidio et Conquestu Britanniae.

${ }^{26}$ Professor emérito da Universidade de Kent, e amplamente reconhecido no campo dos estudos arthurianos.

${ }^{27}$ ANDERSON, King Arthur in Antiquity.

${ }^{28}$ ANDERSON, King Arthur in Antiquity.
}

Revista Vernáculo n. ${ }^{\circ} 43$ - primeiro semestre/2019

ISSN 2317-4021 
uma acepção de que a figura arthuriana é cruzada pelo vetor marcial, e pensamos que isso teve implicações no trabalho de Sir Thomas Malory.

Em 1125, William de Malmesbury (1090/1095-1143) compôs seu De rebus gestis regum Anglorum, e nele Arthur é significativamente aproximado com uma simbologia e imagética do próprio $\mathrm{Cristo}^{29}$. A principal diferença entre Gildas e William de Malmesbury é o contexto social e político da Inglaterra no momento da produção literária. Gildas experimentava uma nova onda de invasões e conquistas saxónicas, portanto um cenário caótico e inseguro.

William de Malmesbury, como pontuou R. M. Thomson ${ }^{30}$, nasceu em uma Inglaterra que experimentava sua fase final de reorganização após a conquista normanda. Isto implicou em uma nova hierarquia eclesiástica que imputou na mudança de "estilo de vida cristão e uma organização modelada nas instituições e no ethos beneditino" "31. Assim, a associação do Rei Arthur com Cristo foi possível, pois existia um pano de fundo religioso que corroborou para tal.

Em 1136, Geoffrey de Monmouth (c. 1095-1155) publicou seu Historia regum Britanniae ${ }^{32}$, obra que estabeleceu uma filiação de

${ }^{29}$ FENTON, Kirsten A., Gender, Nation and Conquest in the Works of William of Malmesbury, Woodbridge: The Boydell Press, 2008.

${ }^{30}$ THOMSON, R. M., William of Malmesbury, Woodbridge: The Boydell Press, 1987.

${ }^{31}$ Tradução nossa. No original: "style of Christian life and organization modelled on the Benedictine institutions and ethos" Ibid., p. 03.

${ }^{32}$ OF MONMOUTH, Geoffrey, History of the Kings of Britain, Cambridge: Medieval Latin Series, 1136.

Revista Vernáculo n. ${ }^{\circ} 43$ - primeiro semestre/2019

ISSN 2317-4021 
Arthur ao mundo clássico, junto com uma narrativa histórica da Inglaterra. Começando desde Brutus, descendente de Enéias, e indo até Cadwaladr (655-682), o autor arquitetou uma base genealógica no mundo clássico greco-romano para a Inglaterra e seu povo. Novos elementos foram integrados na narrativa, sendo o conflito com Roma um deles.

No fim do século XII, Chrétien de Troyes $^{33}$ contribui para a arthuriana de modo significativo. Os seus romances enfatizavam menos Arthur e sim os feitos dos seus cavaleiros e a sociedade que compunham. Em Erec (1170), o foco é Erec, que após atingir certo renome e casar, acaba por perder seu status por não participar mais dos torneios nem executar os feitos que se esperava de um cavaleiro.

A importância da corte ganha mais força em histórias como Cligés (1176) e Yvain (1117). Em Lancelot (1181), o casamento funcionava para atender aos interesses econômicos e políticos, enquanto o amor passava a ser algo negociado, buscado e almejado para fora do matrimônio. Para além destas, Chrétien de Troyes colocou a história de Arthur em direta relação com o Graal, a partir de Percival (1181-1190).

Toda essa contextualização cultural e literária desemboca para Malory, que tem o tom marcial da cavalaria como o seu ponto-chave. A cavalaria e Arthur são indicados a partir de feitos militares. A cavalaria como uma ideia é uma força militar que, em torno de Arthur, serve para constituir o seu reinado bem como o seu nome. O segundo tópico é a

${ }^{33}$ DE TROYES, Oeuvres complètes.

Revista Vernáculo n. ${ }^{\circ} 43$ - primeiro semestre/2019

ISSN 2317-4021 
sociedade que essa cavalaria constrói e na qual é construída - com uma ideia de corte que marcou alianças e antagonismos. Por fim, o terceiro é o cunho religioso, que vai ganhando tom ao longo dos textos de Arthur e também aparece em Malory.

Dorsey Armstrong (1970-), professora de Literatura Inglesa e Medieval da Universidade de Purdue, argumentou que Sir Thomas Malory lida com a questão da cavalaria de um modo específico ${ }^{34}$. Em termos comparativos, o trabalho de Malory diferencia-se da literatura que o precedeu, pois tem um modo de "uma legislação explícita (oposta a uma codificação implícita) dos valores cavalheirescos",35, manifestado pelo Juramento do Pentecostes.

Armstrong, inclusive, visou compreender como a instituição desse juramento foi responsável por definir, como também identificar noções específicas sobre a performance de gênero masculino e feminino dentro da comunidade arthuriana. A hipótese da autora é de que o texto de Malory retrata cavaleiros que eram "engajados num processo perpétuo de contação de histórias como um mecanismo de definir e legitimar a ocupação de cavaleiros e a comunidade cavalheiresca que o mantinha"36. O que significa dizer, com Armstrong, que há uma natureza dupla no texto. Malory parece ter uma percepção que é "tanto

34 ARMSTRONG, Dorsey, Gender and the Chivalric Community in Malory's Morte d'Arthur, Gainesville: University Press of Florida, 2003.

${ }^{35}$ No original: "explicit legislation (as opposed to implicit coding) of chivalric values" Ibid., p. 01.

${ }^{36}$ No original: "engage in perpetual storytelling as a means to define and legitimize the office of knighthood and the chivalric community that supports it". Ibid., p. 06.

Revista Vernáculo n. ${ }^{\circ} 43$ - primeiro semestre/2019

ISSN 2317-4021 
nostálgica quanto cautelar" ${ }^{, 37}$. Assim, as turbulências do período em que Malory vivia e os problemas inerentes da cavalaria são levantados com a criação de um código, um compromisso de lealdade na forma do Juramento de Pentecostes.

O significado desse juramento é, no entender de Armstrong, estabelecer "uma série de parâmetros cavaleirescos para a ação ${ }^{38 ", ~ e ~}$ como se trata de algo que ocorre em um momento relativamente inicial do texto, "o resto da narrativa testa esses valores cavaleirescos"39, visando tensioná-los com as situações do mundo que circunda os cavaleiros. O resultado é a proliferação de tensões em que "o comportamento cavaleiresco e a identidade são exacerbados na medida que o texto desenrola"

Em vista da hipótese de Armstrong, podemos orientar o nosso problema de pesquisa para compreender o que é esse ritual, sua estrutura e funcionamento. A institucionalização da cavalaria em Malory ganhou forma no momento em que há uma corte, composta pelo antagonismo dialógico entre um suserano (o rei) e os seus vassalos (os cavaleiros).

${ }^{37}$ No original: "both nostalgic and cautionary". Tradução nossa.Ibid., p. 07.

${ }^{38}$ No original: "a series of chivalric guidelines into action". Tradução nossa. Ibid.

${ }^{39}$ No original: "the rest of the narrative test those chivalric rules". Tradução nossa. Ibid.

${ }^{40}$ No original: "chivalric behavior and identity are increasingly exacerbated as the text progresses". Tradução nossa. Ibid.

Revista Vernáculo n. ${ }^{\circ} 43$ - primeiro semestre/2019

ISSN 2317-4021 
Richard Barber ${ }^{41}$ demarcou que há três níveis básicos para o funcionamento da cavalaria no contexto que circunda Malory. O primeiro era social, inscrito no âmbito da prática política, bem como das relações econômicas. É a função do guerreiro oferecendo serviço para seu suserano. E, conforme visto em nossa pesquisa até então, um traço fundamental das narrativas de tipo arthuriano.

O segundo nível é do campo ideativo, uma vez que a Cavalaria é uma instituição. Isto significa que há um conjunto de ideias, um núcleo, que fomenta o cavaleiro como alguém "bravo, generoso e cortês" 42 , e formulam aquilo que é o "aspecto cavalheiresco da cavalaria"43. O terceiro nível diz respeito ao papel da religião.

Barber sugeriu que a cavalaria secular, ao traçar relações com a religião, passou a reificar e ser reificada por esta, de modo que era "parte da estrutura social preordenada por Deus" ${ }^{44}$. O resultado foi uma formação militar que operava na medida em que estava apta a "travar guerra secular por razões espirituais" ${ }^{\prime 4}$.

Em vista deste último ponto, retomamos que Jean Flori, ao analisar como o Cristianismo foi ganhando espaço dentro das narrativas Arthurianas de cunho francês, percebeu que isto foi feito pela figura do

${ }^{41}$ BARBER, Richard, Chivalry and the Morte Darthur, in: ARCHIBALD, Elizabeth; EDWARDS, A. S. G. (Orgs.), A Companion to Malory, Cambridge: D. S. Brewer, 1996, p. 19-36.

${ }^{42}$ No original: "brave, generous, and courteous". Tradução nossa. Ibid., p. 22.

${ }^{43}$ No original: "chivalric aspect of knighthood". Tradução nossa. Ibid.

${ }^{44}$ No original: "part of a God's preordained structure of society". Tradução nossa. Ibid., p. 23.

${ }^{45}$ No original: "wage secular war for spiritual reasons". Ibid., p. 51.

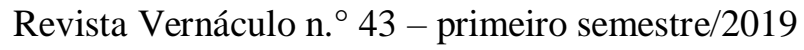

ISSN 2317-4021 
Graal. Assim, "as aventuras dos cavaleiros do Graal tomam uma dimensão escatológica, elas implicam uma humanidade participante dos mistérios da Redenção"46. O que nos leva a perguntar se essa guinada escatológica é um elemento que integra o Juramento de Pentecostes, ou algo externo a ele.

Recolocando nossa questão, partimos do trabalho de Armstrong para perceber que uma das diversas contribuições de Sir Thomas Malory para a narrativa arthuriana é o Juramento de Pentecostes. Tanto Armstrong ${ }^{47}$, quanto Barber ${ }^{48}$ concordam por caminhos diferentes que o interesse de Malory em tensionar e problematizar a Cavalaria acaba levando-o para o afastamento do mundo religioso.

Para Émile Littré ${ }^{49}$, o primeiro sentido do termo "chevalier" está ligado com o mundo clássico romano. Foi somente no medievo que a figura latina do "miles", homem das armas, diferiu do "chevalier" a partir de um tipo de ritual de adubamento. O chevalier estava inscrito dentro de um conjunto de rituais e cerimônias de recepção e transmissão do estatuto social.

${ }^{46}$ No original: "les aventures des chevaliers du Graal prennent alors une dimension eschatologique, elles impliquent l'humanité et participent au mystère de la Rédemption". Tradução nossa. FLORI, Chevaliers et chevalerie au Moyen Age, p. 253.

47 ARMSTRONG, Gender and the Chivalric Community in Malory's Morte d'Arthur.

${ }^{48}$ BARBER, Chivalry and the Morte Darthur.

${ }^{49}$ LITTRÉ, Émile, Dictionnaire de la langue française, Paris: Librairie Hachette et C, 1873, p. 525.

Revista Vernáculo n. ${ }^{\circ} 43$ - primeiro semestre/2019

ISSN 2317-4021 
Esse movimento histórico da vassalagem [vasselage/vaillance], indicado por Littré, no século XI, é o que produzia um cavaleiro. A fonte histórica do lexicógrafo francês foi La Chanson de Roland, poema escrito em francês antigo (c. XI), baseado na batalha de Roncevaux (778) e na morte de Rolando, sobrinho de Carlos Magno (742-814). Todavia, foi somente no século XIII que Littré aproximou a ideia do chevalier ao rito religioso de Pentecostes, a partir das trovas de Rutebeuf (1245-1285).

A definição de Littré é interessante, mas demanda de nossa parte uma depuração em vista de análises específicas sobre o fenômeno da cavalaria. Ressaltamos que seguimos aqui a ideia de Antoine Meillet ${ }^{50}$ sobre as mudanças de sentido em torno de uma palavra.

A linguagem está moldada em transmissões, permanências e rupturas no âmbito social e o "princípio essencial de mudança de sentido está na existência de grupos sociais no interior do meio" ${ }^{, 51} \mathrm{em}$ que uma língua circula, "ou seja, em um fato de estrutura social"52. Exportando isso para nosso caso, recusamos que seja possível produzir uma definição atemporal e meramente formal da cavalaria. Esta precisa, antes de mais nada, ser pensada em seu contexto e função social.

${ }^{50}$ MEILLET, Antoine, Como as Palavras Mudam de Sentido, São Paulo: EDUSP, 2016.

${ }^{51}$ Ibid., p. 75.

${ }^{52}$ Ibid.

Revista Vernáculo n. ${ }^{\circ} 43$ - primeiro semestre/2019

ISSN 2317-4021 
Para Georges Duby ${ }^{53}$, sujeitos inscritos em uma situação social não têm seus comportamentos e sentimentos completamente dominados apenas por sua situação econômica. Pelo contrário, a ação humana é reflexiva, e uma imagem percepcional emerge, que "nunca é uma imagem fiel mas sempre refratada por um jogo complexo de representações mentais" ${ }^{34}$.

No entender de Duby, três categorias sociais estáveis formam a base hierárquica da sociedade medieval. Em forma de pirâmide, o topo seria habitado pelo poder eclesiástico assentado na "superioridade espiritual sobre o temporal" ${ }^{\prime 55}$. Logo abaixo, e mais ampla, o campo marcial, "a ordem dos que combatem, dos que têm por missão defender o conjunto do povo" ${ }^{\$ 6}$, adentrando no campo da cavalaria. Por fim, na ampla base, "a ordem dos camponeses, inteiramente submetida, toda ela vivendo curvada sobre o labor de que se alimentam as outras duas"

Com Duby, podemos afirmar que a Cavalaria é um fenômeno medieval e precisou de um contexto específico para ocorrer. Uma definição tripartite também está presente em Jean Flori, que sugeriu que existiram três "atores" entre os séculos III e VI que contribuíram para a produção de uma Cristandade ocidental. São eles: o substrato cultural

${ }^{53}$ DUBY, As Três Ordens ou O Imaginário do Feudalismo.

${ }^{54}$ Ibid., p. 09.

${ }^{55}$ Ibid., p. 32.

${ }^{56}$ Ibid., p. 33.

${ }^{57}$ Ibid.

Revista Vernáculo n. ${ }^{\circ} 43$ - primeiro semestre/2019

ISSN 2317-4021 
romano, os povos germânicos e a matriz ideológica cristã que atravessa romanos e germânicos, criando uma "nova sociedade" 58 .

O cavaleiro do mundo romano indicado por Littré, não tem mais espaço aqui. A aristocracia romana foi progressivamente recusando "o serviço militar como uma carga insuportável" "59. Em contraste, os povos germânicos "que eram excelentes na guerra e almejavam ingressar no império, procurando empregos para os quais haviam sido treinados desde a infância",60.

A transformação vista por Flori, a partir desta participação cada vez maior dos germânicos nas forças armadas romanas é importante. $\mathrm{O}$ sistema de federalização, empregado para os romanos visando "a integração dos povos migrados fornecendo-lhes o único trabalho que lhes era conveniente e atribuindo-lhes o papel de garantir sua segurança",61.

De modo que as "as elites bárbaras que dominam os principais papéis dentro do domínio militar primeiramente vão vir a ocupar toda a

${ }^{58}$ No original: "nouvelle société". Tradução nossa. FLORI, Chevaliers et chevalerie au Moyen Age, p. 11.

${ }^{59}$ No original: "le service militaire comme une charge insupportable". Tradução nossa. FLORI, Chevaliers et chevalerie au Moyen Age, p. 15.

${ }^{60}$ No original: "qui excellent à la guerre et aspirent à entrer dans l'empire, recherchent au contraire ces emplois pour lesquels ils sont entraînés dès leur enfance". Tradução nossa. Ibid.

${ }^{61}$ No original: "l'intégration de peuples immigrés en leur fournissant le seul travail qui soit à leur convenance et en leur assignant le rôle qu'elle ne peux plus jus, assurer sa protection". Tradução nossa. Ibid.

Revista Vernáculo n. ${ }^{\circ} 43$ - primeiro semestre/2019

ISSN 2317-4021 
cena"62. A célula básica que emergiu é a do rei, acompanhado por seus guerreiros. Padrão que dominaria a Europa, sendo aquilo que "forma as estruturas sociais que são de fato o nascimento da cavalaria" ${ }^{63}$.

Com o Império Carolíngio, a vassalidade foi elevada a uma instituição. Flori explicou que a vassalagem, em um nível mais alto, estrutura a autoridade dos reis carolíngios como "os chefes naturais das unidades territoriais distantes ou dissidentes" ${ }^{\prime 64}$.

E, em outro nível, era um sistema de governo em que as relações locais eram valorizadas, pois "de fato, eles encorajaram todos os seus vassalos diretos a transformar pessoas influentes de sua região em sua vassalagem" "65, permitindo assim que "todos os homens livres escolhessem um senhor" ${ }^{\text {, }}$, que serve como uma representação do poder estatal, e "que os levaria a hoste (exército real) e receberia os impostos" ${ }^{\mathrm{6}}$.

${ }^{62}$ No original: "élites barbares jornet les premier rôles dans le domaine militaire devenu primordial, avant d'occuper toute la scène". Tradução nossa. Ibid., p. 29.

${ }^{63}$ No original: "formées les structures sociales qui ont fait naître le chevalerie". Tradução nossa. Ibid., p. 30.

${ }^{64}$ No original: "les chefs naturels de unités territoriales lointaines ou dissidentes". Tradução nossa. Ibid., p. 43.

${ }^{65}$ No original: "ils ont en effet encouragé tous leurs vassaux directs à faire entrer à leur tour dans leur propre vassalité des personnages influentes de leur région". Tradução nossa. Ibid.

${ }^{66}$ No original: "tous les hommes libres à se choisir un seigneur". Tradução nossa. Ibid. ${ }^{67}$ No original: "qui les mènerait à l'ost (l'armée royale) et recevrait les impôts". Tradução nossa. Ibid.

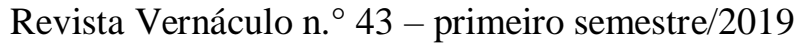

ISSN 2317-4021 
$\mathrm{Na}$ análise feita por Dominique Barthélemy, "os cavaleiros do ano 1100 são todos feudais, senhores e vassalos" ${ }^{\text {68 }}$. A definição principal destes é marcada pelos feitos bélicos, bem como um modo de conduta específico, que se mostra amplamente transgressor tanto em "relação a seus reis e príncipes, ou à igreja que lhes prescreve a guerra santa" ${ }^{\natural 9}$. O cavaleiro, nesse entendimento, é marcado por um tipo de demanda social que "os empurra a se distinguir, a brilhar, a rivalizar em valentia, mas também a colocar condições e limites ao serviço de seu

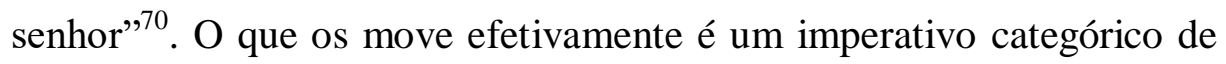
honra. Assim, "cavalaria é apenas um aspecto, entre - e após - outros, da dominação feudal" ${ }^{\prime 1}$.

Seguindo tal argumentação, cavalaria e vassalidade são elementos constitutivos do medievo. Para Barthelemy, vassus e depois vassal são termos tão importantes que quando aplicados implicam, em si, "um estatuto honrável que evoca a valentia guerreira e que traz honra" $" 72$.

A relação com outrem, dentro da vassalidade, é estabelecida por ritos, promessas e um acordo social entre a elite. Interação vassalo e senhor que foi construída de tal modo que constantes "esforços de moderação e de justificação" balizaram os papéis sociais.

${ }^{68}$ BARTHÉlemY, A Cavalaria - Da Germânia Antiga à França do século XII, p. 17.

${ }^{69}$ Ibid.

${ }^{70}$ Ibid.

${ }^{71}$ Ibid.

${ }^{72}$ Ibid., p. 102.

Revista Vernáculo n. ${ }^{\circ} 43$ - primeiro semestre/2019

ISSN 2317-4021 
Mesmo porque, "o serviço do vassalo é para ele uma obrigação" "73, que pode resultar em punições por faltas, desde exílio até morte. Problematizar este modelo histórico em relação ao texto literário de Sir Thomas Malory será essencial para compreender como o funcionamento da instituição da cavalaria operava, considerando que há estruturas imaginárias de permanência histórica que devem guiar a análise.

\section{II}

A elucidação do contexto de Sir Thomas Malory demanda, de antemão, a caracterização do próprio autor. E, no que tange a Malory, a situação não é tão simples quanto parecia de antemão. Em linhas gerais, sabe-se que houve um Sir Thomas Malory que escreveu Le Morte D'Arthur. Mas qual Malory? No período da escrita e publicação do texto, havia, pelo menos, quatro pessoas com este nome.

A identidade do autor não foi confirmada e é um dos principais tópicos de disputa dentre os diferentes estudiosos do assunto. A nossa análise tomou como base o trabalho de William Matthews, que em The Ill-Framed Knight: A Skeptic Inquiry into the identity of Sir Thomas Malory $^{74}$, explicitou como as principais hipóteses surgiram, seu

${ }^{73}$ Ibid.

${ }^{74}$ MATTHEWS, William, The Ill-Framed Knight - A Skeptic Inquiry into the identity of Sir Thomas Malory, Berkeley, Los Angeles: University of California Press, 1966. 
conteúdo bem como defensores, assim como suas estratégias de argumentação e seus problemas.

A primeira hipótese, conforme rastreada por Matthews ${ }^{75}$, pauta pela ideia de que o autor de Le Morte D'Arthur foi Edward Maelor (1586-1620). Quem levantou originalmente essa possibilidade foi Oskar Sommer, em 1890. Mas foi John Rhys, a partir de uma indicação documental, que desenvolveu a ideia. Para Matthews, há, pelo menos, três problemas neste argumento: o texto está em inglês médio (Maelor era galês), não há menções que Thomas Malory era galês, e nos momentos textuais da obra que o autor refere-se a si, evidencia-se que o mesmo se pensava como inglês.

A segunda hipótese mencionada por Matthews ${ }^{76}$ é de que Thomas Malory era oriundo de Papworth (1425-1469), em Huntingdonshire. Essa possibilidade foi proposta pelo antiquário A.T. Martin. Junto com ela Martin elaborou uma biografia para este Malory. Como alertou Matthews ${ }^{77}$, esta tese foi criticada por George Lyman Kittredge e teve mínima aderência, pois o Malory de Papworth não tinha o título de cavaleiro e sim de escudeiro (squire).

A terceira hipótese, que exerce uma certa hegemonia nos estudos atuais, é de que o autor foi Sir Thomas Malory de Newbold Revel (1415-1471). Foi Kittredge que a promulgou, a partir de 1894. Sua consolidação garantiu-se por conta de dois colaboradores, Edward

${ }^{75}$ Ibid.
${ }^{76}$ Ibid.
${ }^{77}$ Ibid.

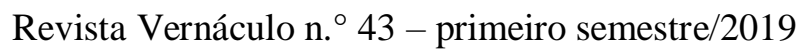

ISSN 2317-4021 
Hicks, que era aluno de Kittredge, e Albert C. Baugh. Sir Thomas Malory de Newbold Revel era um cavaleiro e estava vivo entre 14691470, momento de conclusão da obra. Faleceu antes de 1485, ocasião da publicação de Caxton.

Apesar de cavaleiro, sua vida, conforme foi narrada por Hicks, e retomada por Matthews ${ }^{78}$, passou bem longe do "ideal" cavaleiresco. Acusado de furtos, como cerca de 300 ovelhas e igrejas, emboscadas contra outros nobres e estupro, este Malory passou um período relativamente longo de sua vida preso, fato principal para aqueles que suportam a terceira hipótese. Isto porque no texto de Malory há uma indicação sobre sua autoria, um pedido de oração para o autor que se encontrava prisioneiro. Matthews recolocou que há uma ambiguidade de extrema importância na maneira pela qual Malory requisitará orações em seu texto. Não fica claro que tipo de prisão se tratava, poderia ser algo com "um sentido secular" "79, ou com "sentido espiritual, livre da prisão do corpo" $"$. No mais, Matthews desmontou extensamente cada um dos argumentos que suportam esta causa, demonstrando que nenhum deles pode ser aceito integralmente sem implicar no surgimento de novas dificuldades interpretativas.

A quarta hipótese, que foi defendida pelo próprio Matthews, partiu de um caminho diferente, o dialeto usado na composição da obra.

\footnotetext{
${ }^{78}$ Ibid.

${ }^{79}$ No original: "a secular meaning". Tradução nossa. Ibid., p. 41.

${ }^{80}$ No original: "spiritual meaning, deliverance from the prison of the body". Tradução nossa. Ibid.
}

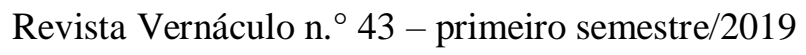

ISSN 2317-4021 
O resultado foi "o autor deve ter vivido no norte e provavelmente em Yorkshire" ${ }^{\prime 81}$. O segundo passo de Matthews foi demonstrar que naquela região havia, no momento de confecção do texto, a presença das fontes utilizadas por Malory, algo que não ocorria na terceira hipótese. Por exemplo, a Mort Arthure Alliterativa e a Le Mort D'Arthur Stanzaic. Duas dessas fontes produzidas em Yorkshire. O terceiro passo de Matthews foi a existência documental de um Thomas Malory, filho de Sir William Malory. Thomas foi prisioneiro de guerra no período da conclusão do texto.

A terceira hipótese implica em um autor que seria de Lancaster, enquanto a quarta nos remete a um apoiador de York. O argumento de Matthews $^{82}$ nos parece o mais forte, mas não precisamos estabelecer um juízo final para compreender que independente de qual delas escolhermos, o autor estava inserido dentro dos conflitos entre barões e reis que marcaram a polarização de uma série de batalhas que, posteriormente, ficaram conhecidas como "Guerras das Rosas".

Quando Henry V (1386-1422), rei da Inglaterra desde 1413, faleceu, deixou o trono para seu filho, de um ano de idade, Henry VI (1421-1471). Quem assumiu o controle do Estado foi John de Lancaster, Duque de Bedford (1389-1435). A situação com a França havia fugido do controle e o poder estatal estava passando da Coroa

\footnotetext{
${ }^{81}$ No original: "the author must have lived in the north and probably in Yorkshire". Tradução nossa.

${ }^{82}$ MATTHEWS, The Ill-Framed Knight - A Skeptic Inquiry into the identity of Sir Thomas Malory.
}

Revista Vernáculo n. ${ }^{\circ} 43$ - primeiro semestre/2019

ISSN 2317-4021 
para o Parlamento. William de La Pole, Duque de Suffolk (1396-1450) foi derrotado pelas forças francesas lideradas por Joana D'Arc (14121431) em 1429, o que implicou em um recuo geral, ao ponto de que em 1453, quase todo o território francês já havia sido retomado ${ }^{83}$.

$\mathrm{Na}$ Inglaterra, o controle da Coroa passou a ser disputado por dois grupos diferentes. De um lado, Humphrey de Lancaster, duque de Gloucester (1390-1447) e de outro, Henry Beaufort (1375-1447), bispo e depois cardeal. O casamento de Henry VI com Margaret de Anjou (1430-1482) foi arquitetado para estabilizar a situação na França, mas implicou na concessão de dezenas de territórios para os franceses, afetando a nobreza inglesa. A rainha passou a ser apoiada pelos Lancaster, e a oposição que se construiu ao seu controle foi liderada por Richard de Conisburgh, Conde de Cambridge e depois Duque de York (1375-1415).

Quando Henry VI cedeu os territórios restantes para os franceses, a autoridade do Conde, que ocupava o posto de comandante militar na Normandia, foi ameaçada. Para conter uma possível retaliação, o comando foi retirado e ele foi enviado para a Irlanda ${ }^{84}$. A partir de 1450, com uma revolta em Londres, as tensões entre as facções aumentou e, em 1461, os York conseguiram tomar o trono e permanecer

${ }^{83}$ HICKS, Michael, The Wars of the Roses 1455-1487, Cambridge: Osprey Publishing, 2003.

${ }^{84}$ POLLARD, A. J., The Wars of the Roses, London: Palgrave Macmillan, 2001.

Revista Vernáculo n. ${ }^{\circ} 43$ - primeiro semestre/2019

ISSN 2317-4021 
até 1471. Os Lancaster encenaram uma retomada breve, que abriu espaço para a vitória final (1485) e o surgimento da dinastia Tudor ${ }^{85}$.

O termo "Guerras das Rosas" é uma invenção romântica e foi criado posteriormente por escritores patrocinados pelo governo Tudor, com interesse propagandístico. Nele, Henry VII (1457-1509) surgiu como uma figura que garantia a paz e a estabilidade em um período caótico $^{86}$. Polydore Vergil (1470-1555), humanista italiano e historiador da corte de Henry VII, em seu Anglica Historia ${ }^{87}$, de 1535, associou a rosa vermelha ao governo Tudor.

Ali, Henry VII defendeu a rosa vermelha, enquanto os Lancaster a branca. Todavia, Henry VII só tomou a rosa vermelha como símbolo depois de sua vitória sobre Richard III. Raphael Holinshed (1529-1580) adotou a ideia de Vergil em seu The Chronicles of England, Scotland, and Ireland ${ }^{88}$, de 1577. Que por sua vez serviu de base para Shakespeare (1564-1616) em seu Henry VI, parte I, em que ocorre o encontro entre o Duque de York e o Conde de Summerset, caracterizados pelas rosas ${ }^{89}$.

${ }^{85}$ WEBSTER, Bruce, The War of the Roses, London: UCL Press Limited, 1998.

${ }^{86}$ POLLARD, The Wars of the Roses.

87 VERGIL, Polydore, Three Book of Polydore Vergil's English History Comprising the Reigns of Henry VI, Edward IV, and Richard III, London: The Camden Society, 1884.

${ }^{88}$ HOLINSHED, Raphael, Chronicles of England, Scotland, and Ireland, London: State Press, 1807.

${ }^{89}$ SHAKESPEARE, William, Willian Shaspeare - Henry VI Parts I, II and III, New York: Modern Liberary, 2007.

Revista Vernáculo n. ${ }^{\circ} 43$ - primeiro semestre/2019

ISSN 2317-4021 
No século XVIII, David Hume (1711-1776) ${ }^{90}$ retomou o termo "Guerra das Rosas", sendo seguido por Sir Walter Scott (1771-1832) em Ivanhoe (1820) e depois em Anne de Geierstein (1890). Scott ${ }^{91}$ falou das rosas como branca para Lancaster e vermelha para York. A popularização da consolidação ocorreu com A Short History of the English People, de John Richard Green (1837-1883) ${ }^{92}$, publicado em 1874.

O termo "Guerras das Rosas" surgiu, portanto, para justificar e legitimar o governo Tudor. Convém lembrar que os conflitos não se encerraram com a vitória em 1485 e Henry VII enfrentou diversas resistências e insurreições contra seu governo. O contexto de Le Morte DArthur e de Sir Thomas Malory, foi, no mínimo, interessante. A posição do rei, de Henry VI até Henry VII, era disputada, e sua autoridade não estava garantida. Assim, quando Malory escrevia, a cavalaria experimentava um grande momento de mudanças e transformações.

\section{III}

Trabalhar com Sir Thomas Malory e sua obra implica compreender a existência, bem como o funcionamento de um campo

${ }^{90}$ HUME, David, The History of England from the Invasion of Julius Caesar to the Revolution in 1688, London: T. Cadell, 1786.

91 LINCOLN, Andrew, Walter Scott and Modernity, Edinburgh: Edinburgh University Press, 2007.

92 GREEN, John Richards, A Short History of the English People, London: Macmillan and Co., 1878.

Revista Vernáculo n. ${ }^{\circ} 43$ - primeiro semestre/2019

ISSN 2317-4021 
específico: Arthurian Studies em sua corrente inglesa. Esse exercício de compreender as camadas da historiografia carregam consigo a ideia que nenhum objeto é "puro", mas composto por camadas de sentido. Com isso deve-se considerar que há correntes teóricas de interpretação, bem como diferentes concepções da função e do desenvolvimento das histórias do Rei Arthur.

Para o medievalista Roger Dalrymple ${ }^{93}$, o campo Arthuriano de língua inglesa se estruturou a partir de três grandes textos: Sir Gawain and the Green Knight, Alliterative Mort Darthur e Le Mort Darthur de Sir Thomas Malory. Dalrymple explicitou que quatro fases principais guiaram a construção deste campo, começando no século XIX e seguindo até os dias de hoje. A primeira linha de interpretação seguiu a emergência dos estudos filológicos e biográficos. Os principais teóricos são Frederic Madden e Frederick Furnivall. A segunda linha de interpretação surgiu em paralelo com a primeira, protagonizada por George Lyman Kittredge e Roger Sherman Loomis, ambos interessados na busca pelas fontes utilizadas pelos autores medievais na produção de suas obras.

Há um grupo paralelo ao arthuriano, influenciado pela escola antropológica britânica, protagonizada por Jessie L. Weston ${ }^{94}$. Além de traduzir diversos textos arthurianos para o inglês moderno, Weston foi

${ }^{93}$ DALRYMPLE, Roger, English Arthurian Literature, in: LACY, Norris J. (Org.), A History of Arthurian Scholarship, Cambridge: D. S. Brewer, 2006, p. 140-157.

${ }^{94}$ WESTON, Jessie L., From Ritual to Romance, New York: Doubleday Anchor Books, 1957.

Revista Vernáculo n. ${ }^{\circ} 43$ - primeiro semestre/2019

ISSN 2317-4021 
influenciada pelo antropólogo Sir James George Frazer ${ }^{95}$. A partir dos trabalhos deste, a autora desenvolveu uma teoria sobre o Santo Graal. Cruzando a ideia de rito presente em autores como von Schroeder, Cumont, Scheftelotizz, Harrison, Sir G. Murray, Anrich e G. R. S. Mead, Weston concluiu que os romances medievais sobre o Graal tratavam-se, na realidade, de ritos de fertilidade antiquíssimos que foram transmitidos do mundo pagão para o cristão ${ }^{96}$. O argumento de Weston exerceu ampla influência nos setores intelectuais no começo do século $\mathrm{XX}$, e depois foi extensivamente criticado.

Para Weston ${ }^{97}$, a questão do Graal precisa ser compreendida a partir de seus aspectos: a Terra Devastada, o Rei Pescador, o Castelo Secreto, a Refeição Comunal, o Instrumento de Alimentação, a Lança Sangrenta e o Copo. Frazer propôs que havia uma semelhança entre a história do Graal e os cultos primitivos da Natureza e Weston explorou isso. Das histórias de Perceval até Gawain, o que se apresentava era a ideia de que a vitalidade do rei estava amarrada com a prosperidade do reino, e quando isso era quebrado, o herói aparecia com a tarefa de restaurar o equilíbrio ${ }^{98}$.

Esse tema que caracterizava as narrativas arthurianas não era uma exclusividade e Weston recuou até os contos indianos (Indra),

${ }^{95}$ FRAZER, James George, The Golden Bough - A Study in Magic and Religion. Part I The Magic Art and the Evolution of Kings, London: MacMillan \& Company, 1911.

${ }^{96}$ WESTON, From Ritual to Romance.

${ }^{97}$ Ibid.

${ }^{98}$ Ibid., p. 23.

Revista Vernáculo n. ${ }^{\circ} 43$ - primeiro semestre/2019

ISSN $2317-4021$ 
gregos (Adonis e Attis), celtas e russos. Com isso, ela expandiu a sua conclusão inicial, sugerindo que há uma relação estrita entre rei e terra que é marcada pela religião: o rei é sagrado ${ }^{99}$.

Como explicou Dalrymple ${ }^{100}$, a partir da segunda metade do século XX, há uma reação às leituras míticas arthurianas. É neste momento que autores como L.D. Benson, J.A. Burrow e R. M. Lumiansky se interessam por interpretações exclusivamente textuais, almejando compreender e elucidar a estrutura das obras. Este terceiro grupo foi influenciado pelas teorias da antropologia estruturalista francesa, liderada por Claude Lévi-Strauss ${ }^{101}$. A quarta fase proposta por Dalrymple pode ser pensada sob o selo do "Criticismo Histórico $^{102}$, que almeja aplicar teorias literárias modernas nos textos medievais. Assim, intérpretes como M.J. Bennet, David Aer, P.J.C Field e Mark Lambert ganharam amplo destaque, além de Carolyn Dinshaw e, mais recentemente, Dorsey Armstrong.

\section{IV}

O Juramento de Pentecostes estabelece um horizonte ideal sobre o que era esperado da cavalaria. Todas as prescrições dadas pelo texto,

${ }^{99}$ Ibid., p. 63.

${ }^{100}$ DALRYMPLE, English Arthurian Literature.

${ }^{101}$ LÉVI-STRAUSS, Claude, Antropologia Estrutural, São Paulo: Cosac-Naify, 2012; LÉVI-STRAUSS, Claude, Antropologia Estrutural Dois, São Paulo: CosacNaify, 2013; LÉVI-STRAUSS, Claude, O pensamento selvagem, São Paulo: Papirus, 1989.

${ }^{102}$ Sobre o Criticismo Histórico e o Novo Criticismo, ver: CASTLE, Gregory, The Blackwell Guide to Literary Theory, Oxford: Oxford University Press, 2007.

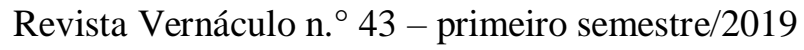

ISSN 2317-4021 
quando lidas em vista do contexto conturbado de produção, revelam a contradição social e cultural que o perpassa. A consolidação de Arthur, como rei, dentro do texto de Sir Thomas Malory, não acontece de uma hora para outra. Não basta retirar a espada da pedra, que inclusive não é excalibur, mas outra. Deve o rei se provar como um exímio guerreiro e ser seguido e venerado por outros guerreiros. Após o seu casamento com Guinevere, a Távola Redonda tornou-se um espaço que organizava a corte e submetia os cavaleiros ao rei.

$\mathrm{O}$ juramento começa com: "than the kynge stablysshed all the knyghtes ${ }^{103 "}$. Stablyshhed - estabelecer - funciona como um processo ritualístico vassálico adaptado para o contexto literário e imagético Arthuriano. Para produzir seus vassalos, estabelecendo-os como tal, é necessário um ato de doação e, portanto, de confiança do rei: "gaff them rychesses and londys ${ }^{104, "}$. A confiança de Arthur em seus cavaleiros foi materializada pela riqueza e pela terra. Partimos do pressuposto de que a riqueza a que se refere, neste momento, está ligada com a fertilidade, e que constitui, posteriormente, a questão do Santo Graal na narrativa.

Para além disto, o contexto histórico do texto de Malory revela a importância das terras para os vassalos dentro do mundo medieval. Um dos motivos para o governo de Henry VI se revelar desastroso, como mencionado, foi a sistemática derrocada das forças inglesas dentro do território que havia sido conquistado na França. O casamento de Arthur

103 VINAVER, Eugène (Org.), The Works of Sir Thomas Malory, Oxford: Clarendon Press, 1947, p. 119.

${ }^{104}$ Ibid.

Revista Vernáculo n. ${ }^{\circ} 43$ - primeiro semestre/2019

ISSN $2317-4021$ 
com Guinevere é o espelho que mostra uma imagem invertida do casamento de Henry VI com Margaret de Anjou. Enquanto o primeiro estabelece a corte de Arthur, e todo seu aparato simbólico, o segundo serviu para marcar o fim das pretensões inglesas dentro da França.

A doação, por parte do rei, implica em estabelecer uma vassalagem que tem um conjunto de normas: "and charged them never to do outerage nothir morthir ${ }^{105, "}$. Charged nos parece como uma forma de mana e hau, no sentido dado por Marcel Mauss ${ }^{106}$ no contexto de trocas melanésio, transportado para o cenário medieval. Como postulou Andrew Cowell, "the gift is essentially a classificatory mechanism ${ }^{107,,}$ que estabelece e sustenta "bonds between various allies, and delineates the enemy as the one to whom one does not give"108. Os cavaleiros que recebem o dom de Arthur, carregados pelo rito vassálico, passam a integrar seu sistema político e social. Outerage e morthir são duas obrigações éticas que, de modo coercitivo, amarram a cavalaria com a questão cortesã.

Segue no juramento que os Cavaleiros devem "allwayes to fle treson" e "to gyff mercy unto hym that askith mercy, uppon payne of

105 Ibid.

${ }^{106}$ MAUSS, Marcel; HUBERT, Henri, Sacrifice: Its Nature and Its Function, Chicago: University of Chicago Press, 1964; MAUSS, Marcel, A Origem dos Poderes Mágicos nas Sociedades Australianas. Estudo Analítico e Crítico de Documentos Etnográficos, São Paulo: Editora da Universidade de São Paulo, 2017; MAUSS, Marcel, Ensaio sobre a Dádiva - Forma e Razão da troca nas sociedades arcaicas, in: Sociol. e Antropol., São Paulo: Cosac-Naify, 2003, p. 183-314.

107 COWELL, Andrew, The Medieval Warrior Aristocracy - Gifts, Violence, Performance, and the Sacred, Cambridge: D. S. Brewer, 2007, p. 07.

${ }^{108}$ Ibid.

Revista Vernáculo n. ${ }^{\circ} 43$ - primeiro semestre/2019

ISSN 2317-4021 
forfiture [of their] workship and lordship of kynge Arthure for evirmore $^{109 "}$. Assim, o vassalo é posto sob o total controle de seu senhor, na medida em que cumpre suas obrigações com o rei. $\mathrm{O}$ juramento tem uma transformação em sua perspectiva, pois passa a falar sobre como os cavaleiros devem se comportar uns perante os outros, algo que remete não apenas à própria corte, mas aos próprios torneios. Não agir de modo cavaleiresco deixa de ser uma ofensa para outrem que é antagônico, para ser ofensivo ao próprio senhor de quem o cavaleiro é vassalo.

O Juramento de Pentecostes, após estabelecer a relação do rei para com os cavaleiros, e destes uns para com os outros, insere a questão feminina: "and allwayes to do ladyes, damesels, and jantilwomen and wydowes [socour] strengthe hem in hir ryghtes ${ }^{110 "}$. Assim, a performance do cavaleiro depende, também, da assistência e proteção às mulheres, que serviram para reificar as ações dos cavaleiros, visto que elas circulam dentro da corte, enquanto os cavaleiros passam a maior parte do tempo fora dela, em aventuras. É em função do romance cortês que a vassalagem ganha sentido.

A segunda orientação vai ainda mais longe: "and never to enforce them uppon payne of dethe ${ }^{111 "}$. Como Armstrong ${ }^{112}$ notou, esta passagem específica não estava presente no texto de William Caxton,

${ }^{109}$ VINAVER (Org.), The Works of Sir Thomas Malory, p. 119.

${ }^{110} \mathrm{Ibid}$.

${ }^{111}$ Ibid.

112 ARMSTRONG, Gender and the Chivalric Community in Malory's Morte d'Arthur.

Revista Vernáculo n. ${ }^{\circ} 43$ - primeiro semestre/2019

ISSN 2317-4021 
apenas no Manuscrito de Manchester. É possível que Caxton tenha suprimido esta passagem, pois visava passar para seu público, uma burguesia emergente, uma noção mais positiva da cavalaria. Todavia, uma proibição só faz sentido se aquilo acontecia dentro da sociedade. Sir Thomas Malory de Newbold Revel, que conforme vimos é aceito por vários dos estudiosos arthurianos como o autor de Le Mort Darthur, acumulou entre suas várias acusações, o estupro. Para William Matthews este é um, entre os vários motivos, para demonstrar que "the man's carrer seems morally discordant with the book ${ }^{113}$ ", uma vez que Malory era um cavaleiro. Mesmo que este não seja o principal argumento de Matthews, o que nos interessa é perceber que, no contexto histórico no qual o livro foi escrito, cavaleiros eram acusados de estupro.

Ao cavaleiro da Távola Redonda, o Juramento também veta o conflito sem sentido, "Also that no man take no batayles in a wrongefull quarell for no love ne for no wordldis goodis" $" 114$. Em nossa perspectiva, parece haver uma transição prescrita dentro da cavalaria neste momento. Um conflito equivocado ou um egoísmo individual que contraria a honra parece preparar o terreno para a relação entre a cavalaria e o sagrado. No mais, o juramento é inclusivo, pois "So unto thys were all knyghtis sworne of the Table Rounde both olde and

${ }^{113}$ MATTHEWS, The Ill-Framed Knight - A Skeptic Inquiry into the identity of Sir Thomas Malory, p. 73.

${ }^{114}$ VINAVER (Org.), The Works of Sir Thomas Malory, p. 120.

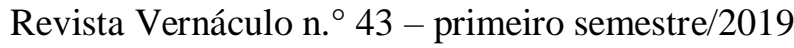

ISSN 2317-4021 
yonge ${ }^{115 \%}$. Outra situação completamente inversa aos conflitos experimentados dentro da Inglaterra no período. As motivações econômicas e políticas dos barões contra os reis são exemplos de batalhas não inscritas dentro daquilo que seria justo.

Sir Thomas Malory encerra demarcando não apenas a ocasião festiva no qual havia ocorrido o evento, mas seu horizonte de repetição: "And every yere so were the[y] sworne at the hygh feste of Pentecoste ${ }^{116 "}$. Não se trata de uma ocorrência singular, mas um tipo de juramento repetido anualmente na festa de Pentecostes, sendo na prática, na conduta dialógica e concreta dos cavaleiros, que a reificação vassalica e cortês da cavalaria ocorrerá.

\section{Conclusão}

O texto de Malory é uma materialidade literária que revela e aponta para problemas históricos que, inscritos no período medieval, seguem para a modernidade. Partido da inscrição marcial da cavalaria, pudemos perceber que o Juramento de Pentecostes serve para marcar a construção de uma ritualização que coloca em jogo elementos culturais e políticos.

Os debates sobre a identidade do autor bem como da existência de Arthur, que como mostramos ocupa parcelas significativas dentro do debate científico contemporâneo, recolocam a capacidade de

\footnotetext{
${ }^{115}$ Ibid.

${ }^{116}$ Ibid., p. 122.
}

Revista Vernáculo n. ${ }^{\circ} 43$ - primeiro semestre/2019 
atualização que a própria narrativa sobre o rei e seus cavaleiros invoca dentro do imaginário. Assim, de um lado o rito demonstra a construção de um campo simbólico de significações e de outro o texto revela a mutabilidade imagética que está presente na cavalaria e vai ganhando novos sentidos ao longo do tempo.

Referências;

ALCOCK, Leslie. Arthur's Britain - History and Archaeology AD 367-634. New York: Penguin Books, 1971.

ANDERSON, Graham. King Arthur in Antiquity. London \& New York: Routledge, 2004.

ARMSTRONG, Dorsey. Gender and the Chivalric Community in Malory's Morte d'Arthur. Gainesville: University Press of Florida, 2003.

ASHLEY, Mike. The Mammoth Book of King Arthur. New York: Carroll \& Graf Publishers, 2005.

BARBER, Richard. Chivalry and the Morte Darthur. In: ARCHIBALD, Elizabeth; EDWARDS, A. S. G. (Orgs.). A Companion to Malory. Cambridge: D. S. Brewer, 1996, p. 19-36.

BARTHÉLEMY, Dominique. A Cavalaria - Da Germânia Antiga à França do século XII. Trad. Néri de Barros Almeida; Carolina Gual da Silva. Campinas: Editora da Unicamp, 2010.

BURLINSON, Christopher. Allegory, Space and the Material World in the Writings of Edmung Spenser. Cambridge: D. S. Brewer, 2006. (Studies in Renaissance Literature, 17). 
CASTLE, Gregory. The Blackwell Guide to Literary Theory. Oxford: Oxford University Press, 2007.

COWELL, Andrew. The Medieval Warrior Aristocracy - Gifts, Violence, Performance, and the Sacred. Cambridge: D. S. Brewer, 2007.

CRAUGHWELL, Thomas J. How the Barbarian Invasions shaped the modern world - The Vikings, Vandals, Huns, Mongols, Goths, and Tartars who Razed the Old World and Formed the New.

Singapore: Fair Wind Press, 2008.

CREIGHTON, John. Britannia - The Creation of a Roman Province. London: Routledge, 2006.

DALRYMPLE, Roger. English Arthurian Literature. In: LACY, Norris J. (Org.). A History of Arthurian Scholarship. Cambridge: D. S. Brewer, 2006, p. 140-157.

DALRYMPLE, Roger (Org.). Middle English Literature - A Guide to Criticism. Malden: Blackwell Publishing, 2004.

DE TROYES, Chrétien. Oeuvres complètes. Paris: Gallimard, 1994.

DUBY, Georges. Ano 1000, Ano 2000 - Na Pista de Nossos Medos. Trad. Eugênio Michel Silva; Maria Regina Lucena Borges-Osório. São Paulo: UNESP, 1998.

DUBY, Georges. As Três Ordens ou O Imaginário do Feudalismo. Trad. Maria Helena Costa Dias. Lisboa: Estampa, 1994.

DUBY, Georges. Sociedades Medievais. Trad. Augusto Joaquim. Lisboa: Terramar, 1999.

FENTON, Kirsten A. Gender, Nation and Conquest in the Works of William of Malmesbury. Woodbridge: The Boydell Press, 2008. 
FLORI, Jean. Chevaliers et chevalerie au Moyen Age. Paris: Hachette Littératures, 1998.

FRAZER, James George. The Golden Bough - A Study in Magic and Religion. Part I The Magic Art and the Evolution of Kings. London: MacMillan \& Company, 1911. 12v.

GILDAS. De Excidio et Conquestu Britanniae. Trad. John Allen Giles. Cambridge: Medieval Latin Series, 540.

GREEN, John Richards. A Short History of the English People. London: Macmillan and Co., 1878.

GREENE, Virginie (Org.). The Medieval Author in Medieval French Literature. New York: Palgrave Macmillan, 2006.

HÉBERT, Marcel. Religious Experience in the Work of Richard Wagner. Trad. C. J. T Talar; Elizabeth Emery. Washington: The Catholic University of America Press, 2015.

HICKS, Michael. The Wars of the Roses 1455-1487. Cambridge: Osprey Publishing, 2003.

HOLINSHED, Raphael. Chronicles of England, Scotland, and Ireland. London: State Press, 1807.

HOWEY, Ann F.; REIMER, Stephen R. (Orgs.). A Bibliography of Modern Arthuriana 1500-2000. Cambridge: D. S. Brewer, 2006.

HUME, David. The History of England from the Invasion of Julius Caesar to the Revolution in 1688. London: T. Cadell, 1786.

LAMBDIN, Laura Cooner; LAMBDIN, Robert Thomas. Camelot in the Nineteenth Century - Arthurian Characters in the Poems of Tennyson, Arnold, Morris, and Swinburne. London: Greenwood Press, 2000.

Revista Vernáculo n. ${ }^{\circ} 43$ - primeiro semestre/2019 ISSN $2317-4021$ 
LAYCOCK, Stuart. Britannia The Failed State - Tribal Conflcits and the End of Roman Britain. Stroud: The History Press, 2008.

LÉVI-STRAUSS, Claude. Antropologia Estrutural. Trad. Beatriz Perrone-Moisés. São Paulo: Cosac-Naify, 2012.

LÉVI-STRAUSS, Claude. Antropologia Estrutural Dois. Trad. Beatriz Perrone-Moisés. São Paulo: Cosac-Naify, 2013.

LÉVI-STRAUSS, Claude. O pensamento selvagem. São Paulo: Papirus, 1989.

LINCOLN, Andrew. Walter Scott and Modernity. Edinburgh:

Edinburgh University Press, 2007.

LITTRÉ, Émile. Dictionnaire de la langue française. Paris: Librairie Hachette et C, 1873. 3v.

MALORY, Sir Thomas. Le Morte D'Arthur. Vol. 1-2. London: Penguin Books, 1969.

MATTHEWS, William. The Ill-Framed Knight - A Skeptic Inquiry into the identity of Sir Thomas Malory. Berkeley, Los Angeles: University of California Press, 1966.

MAUSS, Marcel. A Origem dos Poderes Mágicos nas Sociedades Australianas. Estudo Analítico e Crítico de Documentos Etnográficos. Trad. Fernando Marcial Ricci Araújo; Rafael Faraco Benthien. São Paulo: Editora da Universidade de São Paulo, 2017.

MAUSS, Marcel. Ensaio sobre a Dádiva - Forma e Razão da troca nas sociedades arcaicas. In: Sociol. e Antropol. São Paulo: Cosac-Naify, 2003, p. 183-314.

MAUSS, Marcel; HUBERT, Henri. Sacrifice: Its Nature and Its Function. Trad. W. D. Hall. Chicago: University of Chicago Press, 1964. 
MEILLET, Antoine. Como as Palavras Mudam de Sentido. São Paulo: EDUSP, 2016.

OF MONMOUTH, Geoffrey. History of the Kings of Britain. Trad. Aaron Thompson; John Allen Giles. Cambridge: Medieval Latin Series, 1136.

POLLARD, A. J. The Wars of the Roses. London: Palgrave Macmillan, 2001.

SAWYER, P. H. King and Vikings - Scandinavia and Europe AD 700-1100. London \& New York: Routledge, 1982.

SAYLE, C. E. Early English Printed Books in the University Library, Cambridge, 1475 to 1640. Vol. 1: Caxton to F. Kingston. Cambridge: Cambridge University Press, 1900.

SHAKESPEARE, William. Willian Shaspeare - Henry VI Parts I, II and III. New York: Modern Liberary, 2007.

THOMSON, R. M. William of Malmesbury. Woodbridge: The Boydell Press, 1987.

VERGIL, Polydore. Three Book of Polydore Vergil's English History Comprising the Reigns of Henry VI, Edward IV, and Richard III. London: The Camden Society, 1884.

VINAVER, Eugène (Org.). The Works of Sir Thomas Malory. Oxford: Clarendon Press, 1947. 3v.

WEBSTER, Bruce. The War of the Roses. London: UCL Press Limited, 1998.

WESTON, Jessie L. From Ritual to Romance. New York: Doubleday Anchor Books, 1957.

Recebido em 10/09/18 aceito para publicação em 01/02/19 